\section{Pattern of Antibiotics Use at the Primary Health Care Level of Bangladesh: Survey Report-1}

S. M. Raquibul Hasan ${ }^{1 *}$, Md. Mokarram Hossain ${ }^{1}$, Raushanara Akter ${ }^{1}$ S. M. Hasibul Karim ${ }^{2}$, Shamsul Haque ${ }^{1}$, Md. Kamaluddin ${ }^{1}$, Abdul Ghani ${ }^{1}$

Department of Pharmacy, Stamford University Bangladesh ${ }^{1}$ 51 Siddeswari Road, Dhaka-1217

Department of Statistics, Jahangirnagar University ${ }^{2}$

Savar, Dhaka-1342
*Corresponding Author

S. M. Raquibul Hasan

Lecturer, Dept. of Pharmacy

Stamford University Bangladesh

Contact no.: +8801716487173

E-mail: smraquib 1114@yahoo.com

Received- 5 March, 2009

Accepted for Publication-10 April, 2009

\begin{abstract}
Although Bangladesh has made substantial progress in drug manufacturing since the introduction of its National Drug Policy (NDP) in 1982, irrational use of drugs, inappropriate prescribing, inadequate access to essential drugs and unjustified self medication are a few of a range of problems that are affecting the total health care system seriously. Taking this in view, a survey project has been designed to conduct nationwide to explore the pattern of antibiotics use at the primary health care level in Bangladesh using carefully constructed questionnaires containing questions covering both antibiotic prescription habit of the physicians and patients' response to antibiotic use. In the first phase of this effort, 20 Upazila Health Complexes and the Union Health Centres thereunder each of Dhaka and Chittagong division were randomly surveyed. From physician survey it was evident that $55.57 \%$ of the doctors prescribe antibiotics in suspected infection while only $33.46 \%$ of them prescribe antibiotics in confirmed cases. $40.22 \%$ of doctors prescribe antibiotics in cold and fever before any diagnostic test. Moreover, $37.31 \%$ of doctors prescribe antibiotics for pleasing the patients whereas $62.44 \%$ denied such undue influence. Doctors seldom receive feedback of completion of course of antibiotic therapy by patients. Cephalosporin was found to be the most $(26.9 \%)$ preferred antibiotic in case of empirical therapy. On the other hand, it was evident from patient survey that cold, fever and acute respiratory infection (ARI) were prevalent (39.78\%) causes that brought the patients to physician. $60.1 \%$ of the patients reported that they get essential antibiotics from hospital free of cost while $24.5 \%$ of them complained that they do not get antibiotics from hospital. $34.76 \%$ of the patients reported that they complete the course of antibiotic therapy by buying antibiotics from the market whereas $56.14 \%$ of them do not buy the full course and stop taking medicine (53.46\%) as soon as symptoms subside. The results of the present survey indicate that antibiotics are widely and inappropriately used without following standard guidelines or based on any rationality. This is an alarming situation, which should be properly taken care of by the relevant authority to save the people from growing antibiotic resistance.
\end{abstract}

Key words: Bangladesh, Rational use, Antibiotics, Primary health care.

\title{
INTRODUCTION
}

Bangladesh is a developing country with more than $75 \%$ of the total population living in rural areas containing $82 \%$ of the total poor people. About $36 \%$ of the population continue to live below the national poverty line ( $<\cup S \$ 1 /$ day). Basic needs of living particularly health and education remain largely unmet and only less than $40 \%$ of the population has access to basic healthcare (Islam, 2006; WHO, 2006). The administration of primary health care by the Bangladesh government is carried out through a surprisingly extensive infrastructure of facilities within each of the 64 districts. The districts are divided into 460 upazilas (sub-district) which are subdivided into unions. Each union consists of approximately 25,000 people and health services are directed by the Ministry of Health and Family Welfare (MOHFW). The upazilas (sub-district) consisting of unions, represent the rural areas of the country. Primary health care service is offered from the union levels called 'Union Health Centers'. Union Health Centers have an available staff comprising of a Medical Assistant, who receives three years of training in disease prevention, health education, and basic first aid, and a Family Welfare Visitor, who receives 18 months of training in family planning, reproductive health, and postnatal and prenatal care. However, despite such an extensive rural health care infrastructure, only a diminutive fraction, as little as 8 percent of the rural population access these amenities (Perry, 2000). In response to WHO's essential drugs concept such as 
access to essential medicines, quality of all medicines and rational use of drugs (WHO, 2003), Bangladesh pioneered a National Drug Policy (NDP) in 1982. Main objectives of this policy were to ensure easy accessibility to essential drugs with affordable price, standard quality of drugs and rational use of drugs through appropriate prescribing and dispensing by the health care professionals (Islam, 2006).

Despite the fact that majority of the population live in rural areas, the government health care system remains a very minor source of health care there (Roy, 1997). In many developing countries including Bangladesh, well-trained health personnel are scarce and cannot serve the entire population, particularly in rural areas (Pearson, 1995). Again, around $26 \%$ of professional posts in rural areas remain vacant and there is high rate of absenteeism (about $40 \%$ ). Treatments in the rural areas are mainly (about $45 \%$ ) provided by unqualified health personnel including medical assistants, mid-wives, village doctors, community health workers in comparison to that by qualified medical graduates (only 10-20\%) (Ahmed, 2005). Unskilled personnel are less aware of the deleterious effects of inappropriate antibiotic use. Over-prescribing and inappropriate prescribing are very common in the country due to unethical practices of both health professionals and drug manufacturers (Ahmad, 2003). Unqualified drug sellers offer alternative drugs when the prescribed drugs are out of stock or refill prescriptions without consulting the prescriber (Kigotho, 1997; Dua et al., 1994). A high proportion of patients in some developing countries are treated by untrained practitioners simultaneously with oral and injectable antibiotics administered with contaminated needles and syringes (Rahman et al., 1998) for misdiagnosed noninfectious diseases (Fagbule and Kalu, 1995). In most developing countries including Bangladesh, antibiotics can be purchased without prescription, even when the practice is not legal. In many African, Asian, and Latin American countries, antibiotics are readily available on demand from hospitals, pharmacies, patent medicine stalls (drugstores), roadside stalls, and hawkers (Dua et al., 1994; Lansang et al., 1990). In rural Bangladesh, for example, 95\% of drugs consumed for 1 month by more than 2,000 study participants came from local pharmacies; only $8 \%$ were prescribed by physicians (Hossain et al., 1982). People are encouraged to buy from unofficial distributors because drugs often are not available in government hospitals. Drug vendors usually have little or no knowledge of the required dosage regimen, indications, or contraindications (Goel et al., 1996; Haak, 1988). Based on the prevailing situation and practice, the present survey was conducted to have a sight at the severity of the situation while putting forward some recommendations in this regard.

\section{MATERIALS AND METHODS}

\section{Sample Selection}

20 Upazila Health Complexes and Union Health Centres each under respective upazila of Dhaka and Chittagong divisions were conveniently surveyed at the first phase as part of our ongoing nationwide survey. In total, 40 Upazila Health Complexes and 200 Union Health Centres were covered. One student representative was selected and assigned for individual upazila to carry out the survey. Each representative was provided with questionnaire sheets. A total of 760 questionnaires were processed from physician survey and a total of 8000 questionnaire sheets from patient survey were considered. In Upazila Health Complexes, registered doctors were interviewed but in Union Health Centres, Medical Assistants and other healthcare professionals, who are responsible for patient healthcare service, were included. Sixty questionnaires were excluded during data analysis because of inadequate information.

\section{Data Collection and Analysis}

This paper and pencil survey consisted of open, closed ended and multiple choice questions. An English language survey was developed based on information drawn from relevant literatures pertaining to rational use of antibiotics at the primary health care level of some developing countries. Separate questionnaires were prepared for physician and patient survey. Questionnaire for physicians covered their tendency to make antibiotic prescription in terms of frequency, disease severity, justification of the ground of antibiotic prescription at any given clinical condition and other relevant information. On the other hand, questionnaire for patient survey covered basic questions related to their illness, their trend to stick to doctor's prescription and related information. The representatives were trained to ask the potential respondents about the purpose and other details of the study. Questionnaires were given only to the spontaneously interested candidates during the survey. The participants were requested to respond to the questions; then the questionnaires were 
filled up by the representatives and were collected accordingly later from the same representatives. The survey questionnaires were pilot-tested prior to the main survey. The data was subjected to simple descriptive statistical analyses including frequency distribution, mean, standard deviation and percentage, since the purpose of the study was not to generalize the findings.

\section{RESULTS}

From physician survey, it was evident that $55.57 \%$ of the doctors prescribe antibiotics in suspected infection whereas $33.46 \%$ of them prescribe antibiotics after an infection has been ascertained (Figure 1). Again, $40.22 \%$ of doctors reported that they prescribe antibiotics in cold and fever before diagnosis (Figure 2). However, $37.31 \%$ of doctors admitted that they prescribe antibiotics for patient satisfaction while $62.44 \%$ ruled out such possibilities. Doctors rarely (24.38\%) get to receive feedback of completion of course of antibiotic therapy by patients (Figure $3)$. In case of empirical therapy, cephalosporin was found to be on the top of choice (26.9\%) of doctors. $17.40 \%$ of doctors marked over prescription as a cause of antibiotic resistance but most of them identified patient non compliance (65.20\%) to be the prime cause while $10.84 \%$ supported that it might be due to wrong selection of antibiotics too (Figure 4).

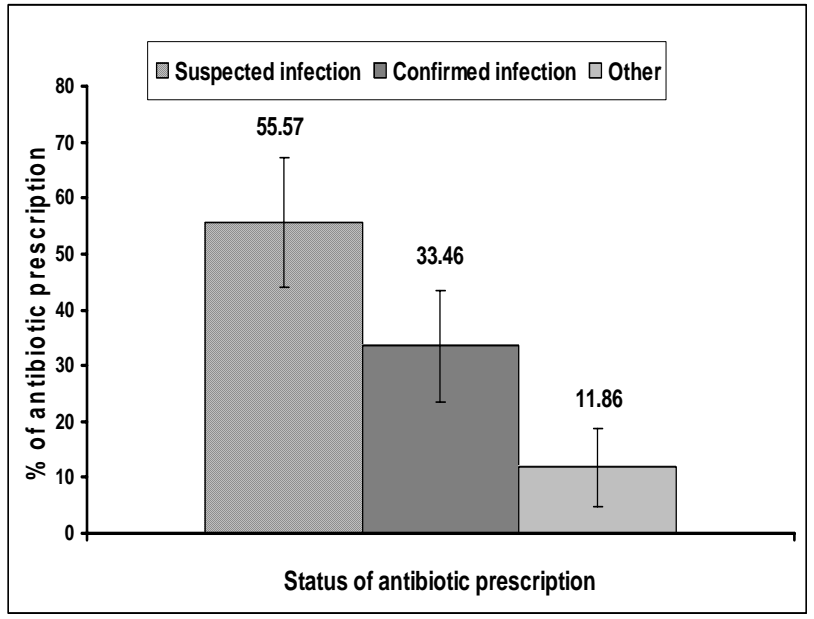

Figure-1. Response to the clinical situation for choosing an antibiotic prescription

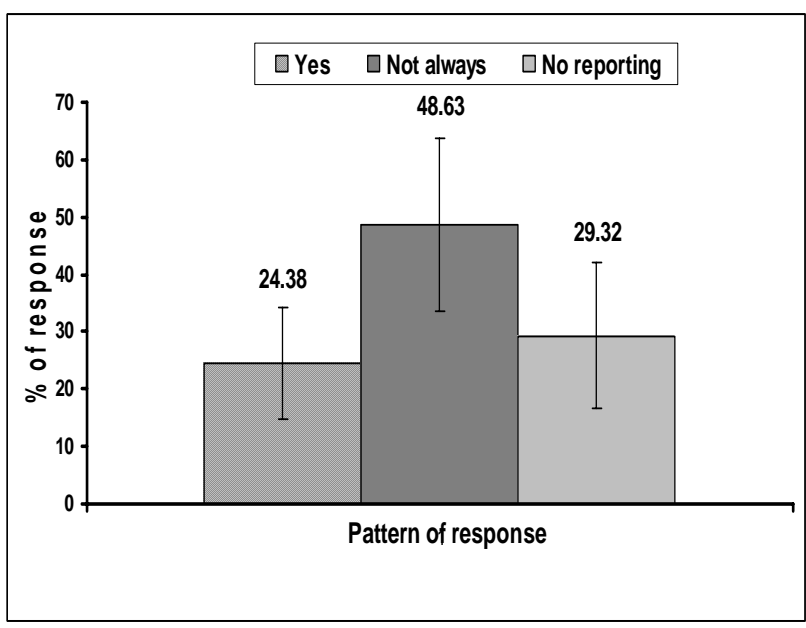

Figure-3. Response to the patients' feedback for the completion of course of antibiotic therapy

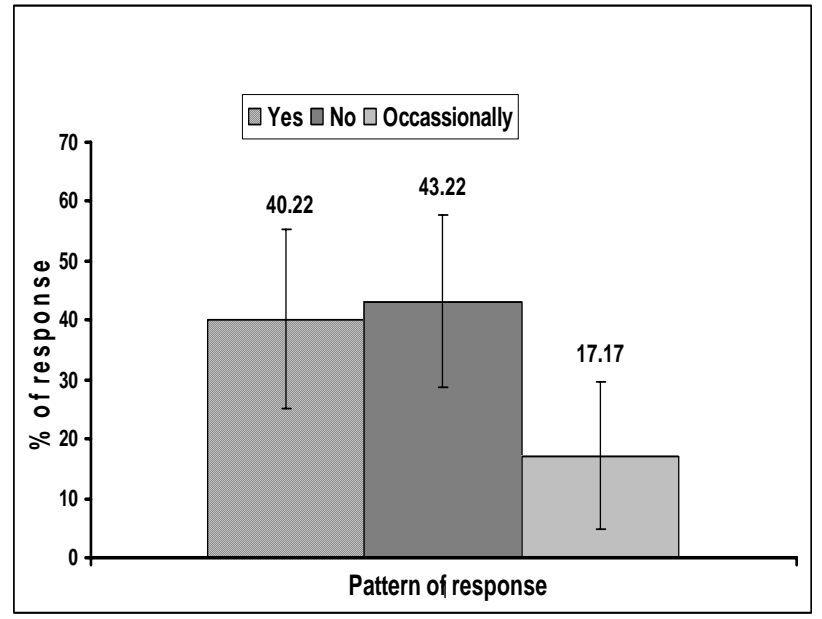

Figure-2. Response to antibiotic prescription in Cold/Fever/ARI before diagnostic tests.

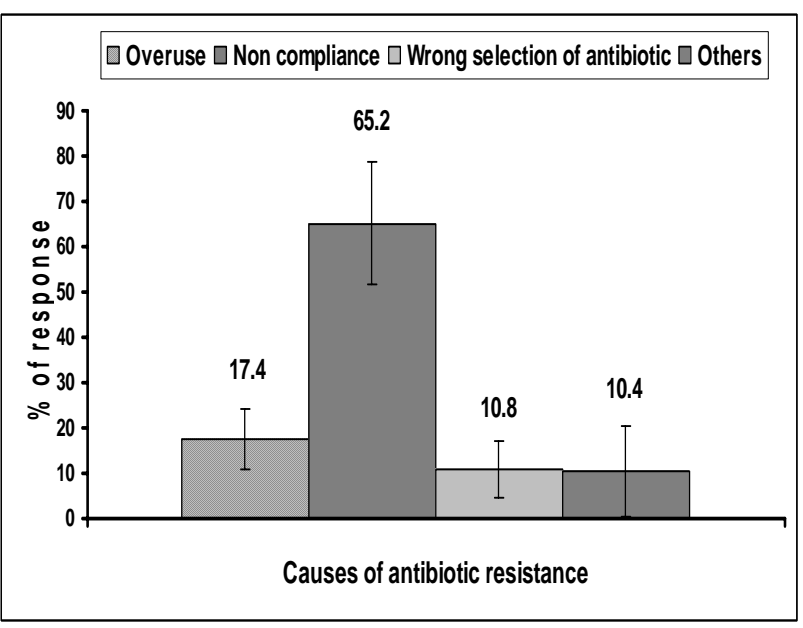

Figure-4. Response to the causes of antibiotic resistance

Figures. Selected responses from physician survey 


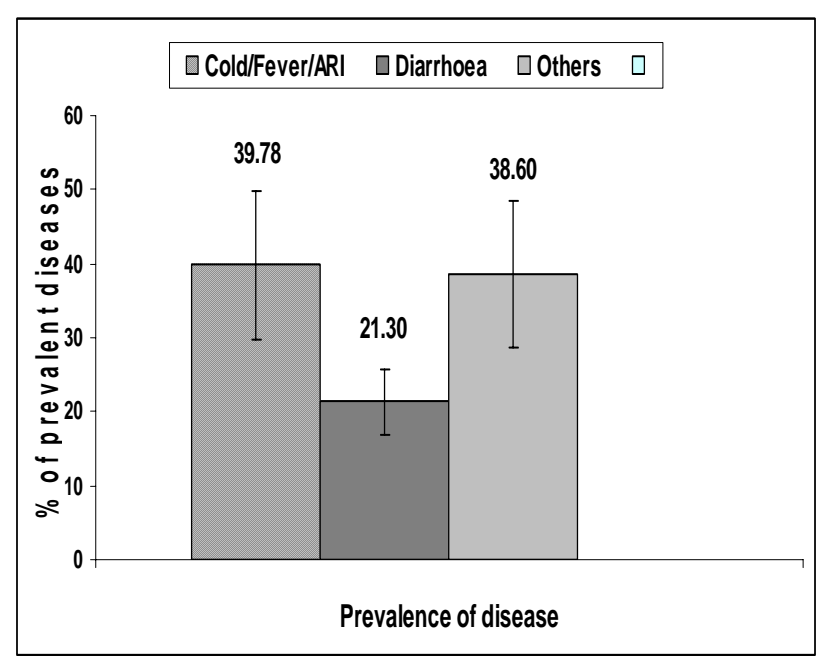

Figure-5. Reasons behind patients' visit to doctors

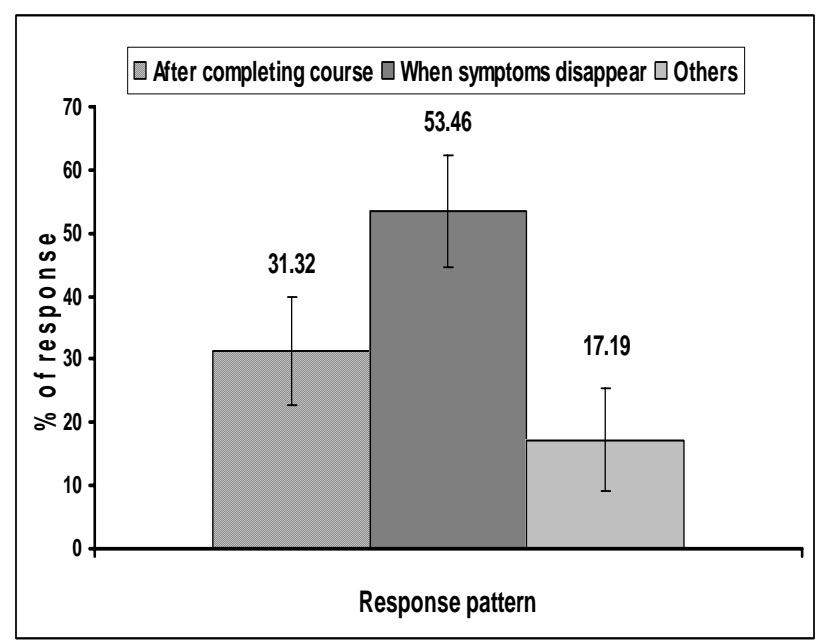

Figure-7. In response to the time of stopping to take antibiotics by patients

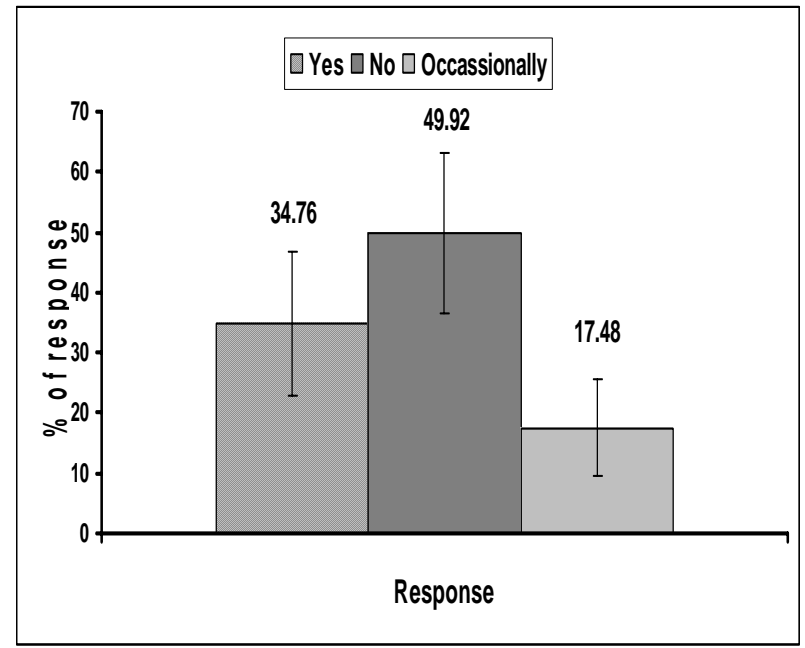

Figure-6. Percentage of patients taking full course of antibiotic therapy

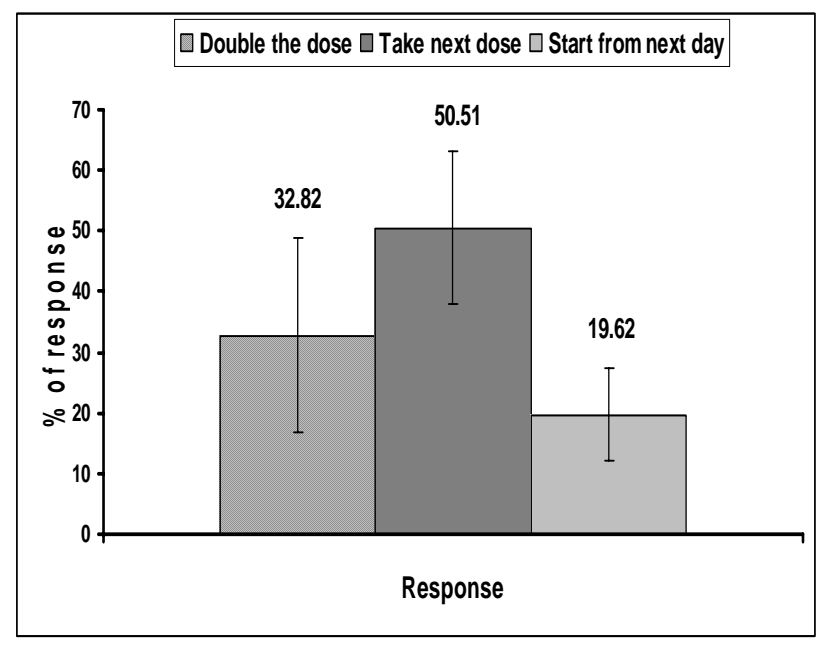

Figure-8. Patients' action when they miss a dose of an antibiotic.

\section{Figures. Selected responses from patient survey}

On the other hand, it was seen from patient survey that cold, fever and acute respiratory infections (ARIs) were prevalent $(39.78 \%)$ causes that brought the patients to physician, followed by these was diarrhoea which was found to be as high as $21.3 \%$ ((Figure 5). However, $60.1 \%$ of the patients reported that they get essential antibiotics from hospital free of cost while $24.5 \%$ of them complained that they do not get antibiotics from hospital. $34.76 \%$ of the patients buying full course of antibiotics reported that they complete the course of therapy whereas $56.14 \%$ of them do not buy the full course and stop taking medicine (53.46\%) when symptoms disappear (Figures 6, 7). Interestingly enough, $32.82 \%$ of patients reported that they just double the dose of antibiotics if they miss the previous dose in an attempt to compensate for that, whereas $50.51 \%$ take the next dose and continue according to the schedule (Figure 8).

\section{DISCUSSION}

Although antibiotic use in clinical practice alone cannot explain the high frequency of resistant organisms in developing countries, excessive clinical use (a form of misuse) is at least partially responsible for the escalating rates of resistance, especially in hospital settings, worldwide (Guyon et al., 1994). The unnecessary prescription of antibiotics seen in industrialized nations has also been documented in many developing countries, particularly in cases of acute infantile diarrhea and viral respiratory infections (Bojalil and Calva, 1994; Hui et al., 1997). Health workers in many 
developing countries including Bangladesh have almost no access to objective health information (Cash, 1996). Pharmaceutical company representatives typically outnumber practitioners and often adversely influence their prescription habits (Ronsmans, 1996), as reflected by sales of nonessential drugs and drug combinations (Hartog, 1993). However, to save time and keep drughunting to a minimum, a patient may start at a source more likely to stock the desired drug, forgoing the expertise of a doctor. Unofficial sources are generally more accessible than official sources. Alternate sources offer the option of purchasing small quantities of medicines, while hospitals require purchase of the complete 5- or 7-day antibiotic regimen (Bojalil and Calva, 1994; Dua et al., 1994). The purchase of small samples is exceedingly common, particularly for most customers, who buy without prescription (Lansang et al., 1990). These subinhibitory antibiotic regimens predispose for selection of resistant bacterial strains.

The motives for self-medication and antibiotic overuse by laypersons are similar to those for clinical abuse by health professionals: to cut costs and act expeditiously to treat confirmed or suspected bacterial infection (Abosede, 1984). For example, $50 \%$ to $80 \%$ of Bangladeshi patients infected with Shigella admitted that they had taken at least one antibiotic in the 15 days before a hospital visit (Shahid et al., 1985), as had $18 \%$ to $70 \%$ of pediatric patients with acute respiratory infection in two Chinese studies (Hui et al.1997; Yang et al., 1993).

The most important cause, as reported by the physician in this survey, of antibiotic abuse and selection for resistant bacteria is poor patient compliance which might be a result of several underlying causes: first, physician-patient interactions are often inadequate. They can be short as brief as a mean of $54 \mathrm{sec}$ as was recorded in a Bangladeshi study (Guyon, 1994) and of poor quality which was documented form a study in Mexico, where poor patient-physician communication was partially responsible for the noncompliance of patients with antibiotic regimens (Reyes et al., 1997). Second, because patients often travel long distances and incur large expenses for medical care, they are unlikely to return for follow-up visits. Finally, because many drugs are expensive, indigent patients purchase incomplete regimens whenever possible and discontinue treatment when symptoms disappear but before the pathogen is eliminated (Lansang et al., 1990).

In developing countries, political corruption and mismanagement of funds, personnel, and development programs have created large populations living in abject poverty and at high risk for infection. Medical expenses, days lost from work, and transportation costs account for substantial economic loss. The cost of medical treatment, even subsidized treatment, is beyond the means of many patients. Poorly paid health workers sometimes extort fees from patients. Thus, persons with communicable diseases, unable to afford medical treatment, may infect others. Poverty also interferes with patient compliance, which in turn promotes the emergence of antibiotic resistance during short-term therapy of acute infections and long-term therapy of chronic infections, such as tuberculosis (Cornwall, 1997). The recommendations of WHO for ensuring proper drug use can be adopted to combat irrational use of antibiotics and the escalation of community-acquired antibiotic resistance in developing countries (Couper, 1997). The misuse of antibiotics by health-care professionals, unskilled practitioners, and patients can be alleviated by auditing antibiotics, limiting antibiotic choice, developing prescription guidelines, and emphasizing continuing medical and public education.

Patterns of antibiotic prescribing, uses, availability, affordability and dispensing in Bangladesh are very crucial at present. The existing systems should be reformed in order to ensure better utilisations of antibiotics including other therapeutic drugs in the country. The following recommendations can be suggested based on the present study: an interdisciplinary approach involving physicians, nurses, pharmacists, economists, sociologists, communication specialists, manufacturers and others should address the problem of inappropriate use of antibiotics; the policy makers, manufacturers and the medical professionals should be committed to uphold the status of public health systems of the country through implementation of the noble objectives of the NDP; the government should ensure a steady supply of good quality essential medicines in the government health care facilities; mass media like radio, television and newspapers can be used to create awareness and to educate the consumers about dos and don'ts of rational drug uses; participation of local and international NGOs is necessary to promote high quality and rational use of drugs; drug sellers should be trained properly to minimize inappropriate drug dispensing and recommendations (Islam, 2006). 


\section{CONCLUSION}

These findings are likely to be representative of the pattern of antibiotic use in rural Bangladesh. Similar surveys should be undertaken to cover the whole of Bangladesh, to monitor inpatient prescribing and care, and to investigate the antibiotic use pattern inside and outside of healthcare set up.

\section{REFERENCES}

Abosede OA. (1984) Self-medication: an important aspect of primary health care. Soc.Sci .Med.19:699-703.

Ahmad A. (2003) Provision of Primary Health Care in Bangladesh: An Institutional Analysis. Paper presented at the Conference on Development Research at Lund University. Sweden. (URL: http://ideas.repec.org/p/hhs/lunewp/2003_018.html).

Ahmed SM. (2005) Exploring Health-seeking behaviour of disadvantaged populations in rural Bangladesh (PhD Dissertation, No. 05/433). Karolinska University Press. Sweden. (URL: http://diss.kib.ki.se/2005/91-7140-435-X/).

Bojalil R, Calva JJ. ( 1994) Antibiotic misuse in diarrhea. A household survey in a Mexican community. J. Clin. Epidemiol. 47:147-56.

Cash R.( 1996) Inappropriate treatment for dysentery. BMJ. 313:181-2.

Cornwall J.(1997) Tuberculosis: a clinical problem of international importance. Lancet. 350:660-1.

Couper MR. (1997) Strategies for the rational use of antimicrobials. Clin. Infect. Dis. 24 Suppl 1:S154-6.

Dua V, Kunin CM, White LV. (1994) The use of antimicrobial drugs in Nagpur, India. A window on medical care in a developing country. Soc. Sci. Med. 38:717-24.

Fagbule D, Kalu A. (1995) Case management by community health workers of children with acute respiratory infections: implications for national ARI control programme. J. Trop. Med. Hyg. 98:241-6.

Goel P, Ross-Degnan D, Berman P, Soumerai S. (1996) Retail pharmacies in developing countries: a behavior and intervention framework. Soc. Sci. Med.42:1155-61.

Guyon AB, Barman A, Ahmed JU, Ahmed AU, Alam MS. (1994) A baseline survey on use of drugs at the primary health care level in Bangladesh. Bull. World Health Organ.72:265-71.

Haak H. (1988) Pharmaceuticals in two Brazilian villages: lay practices and perceptions. Soc. Sci. Med. 27:1415-27.

Hartog R. (1993) Essential and non-essential drugs marketed by the 20 largest European pharmaceutical companies in developing countries. Soc. Sci. Med. 37:897-904.

Hossain MM, Glass RI, Khan MR. (1982) Antibiotic use in a rural community in Bangladesh. Int. J. Epidemiol. 11:402-5.

Hui L, Li XS, Zeng XJ, Dai YH, Foy HM. (1997) Patterns and determinants of use of antibiotics for acute respiratory tract infection in children in China. Pediatr. Infect. Dis. J. 16: 560-4. 
Islam MS. (2006) A Review on the Policy and Practices of Therapeutic drug Uses in Bangladesh. Calicut Med. J. 4(4):e2.

Kigotho AW. (1997) Ugandan doctors request antibiotic moratorium. Lancet. 350:1014.

Lansang MA, Lucas-Aquino R, Tupasi TE, Mina VS, Salazar LS, Joban N. (1990) Purchase of antibiotics without prescription in Manila, the Philippines. Inappropriate choices and doses. J. Clin. Epidemiol.43:61-7.

Pearson CA. (1995). The role of district hospitals and the action in international medicine network. Infect. Dis. Clin. North Am. 9:391-405.

Perry, Henry B. (2000). Health for all in Bangladesh. Dhaka: University Press Ltd.

Rahman F, Andersson R, Svanstrom L. (1998) Medical help seeking behaviour of injury patients in a community in Bangladesh. Public Health. 112:31-5.

Reyes H, Guiscafre H, Munoz O, Perez-Cuevas R, Martinez H, Gutierrez G. (1997) Antibiotic noncompliance and waste in upper respiratory infections and acute diarrhea. J. Clin. Epidemiol. 50:1297-304.

Ronsmans C, Islam T, Bennish ML. (1996) Medical practitionersí knowledge of dysentery treatment in Bangladesh. BMJ. 313:205-6.

Roy J. (1997) Health status, treatment and drug use in rural Bangladesh: a case study of a village. Australian J. Rural Health. 5(2):70-5

Shahid NS, Rahaman MM, Haider K, Banu H, Rahman N. (1985) Changing pattern of resistant Shiga bacillus (Shigella dysenteriae type 1) and Shigella flexneri in Bangladesh. J. Infect. Dis.152:1114-9.

World Health Organization (WHO), World Health Statistics (2006), Geneva. (URL: http://www.who.int/entity/whosis/whostat2006/en/index.html).

World Health Organization (WHO). Policy perspective on medicines -How to develop and $\begin{array}{llll}\text { implement a national drug } & & & \end{array}$ Geneva.(URL:http://www.who.int/medicines/publications/policyperspectives/PPM_No66pg-en.pdf).

Yang YH, Fu SG, Peng H, Shen AD, Yue SJ, Go YF. (1993) Abuse of antibiotics in China and its potential interference in determining the etiology of pediatric bacterial diseases. Pediatr. Infect. Dis. J.12:986-8. 